\title{
Learning to navigate and enriching the research process by engaging in a collaborative practice research capacity strategy
}

\author{
Lianne P. Jeffs*1,2, Beverly Bulmer ${ }^{2}$, Maria Maione ${ }^{2}$ \\ ${ }^{1}$ Keenan Research Centre, Li Ka Shing Knowledge Institute, St. Michaels Hospital, Toronto, Canada \\ ${ }^{2}$ St. Michael's Hospital, Toronto, Canada
}

Received: February 26, 2018

DOI: $10.5430 /$ jnep.v8n10p48

\author{
Accepted: May 3, 2018 \\ Online Published: May 14, 2018 \\ URL: https://doi.org/10.5430/jnep.v8n10p48
}

\begin{abstract}
Engaging regulated health professionals in research is associated with greater service efficiencies and positive patient outcomes (reduced patient mortality and morbidity). This paper provides the results from a study undertaken to explore the perspectives and experiences of nurses and health disciplines participating in a collaborative practice based research (CPBR) capacity building educational program. The purpose of this study was to explore the perceptions and experiences of nurses and other health disciplines in an interprofessional, collaborative research capacity building strategy. The interviews were analyzed using an inductive, thematic analysis process. Twelve members participating in the CPBR program who were female with 5 nurses, 3 occupational therapists, 2 social workers, 1 speech language pathologist and 1 research coordinator were recruited for the study. The following five themes emerged from the data: 1) learning to navigate the research landscape in a shared space; 2) providing an opportunity and support for interprofessional clinician driven research; 3) enriching the research process by engaging different professions to collaborate; 4) impacting current and future collaborative practice; and 5) keeping the momentum amidst experiencing challenges. Our study demonstrated the value of providing opportunity for nurses and health disciplines to engage in collaborative practice based research and undertake a project relevant to clinical practice that adds to the body of knowledge on the value of collaborative practice based research capacity building strategies and communities of practice.
\end{abstract}

Key Words: Interprofessional collaboration, Interprofessional research, Mixed methods, Capacity building

\section{INTRODUCTION}

Having a strong research culture that engages regulated health professionals in research is associated with greater service efficiencies and positive patient outcomes (reduced patient mortality and morbidity). ${ }^{[1-3]}$ Over the last decade, several research capacity assessment and strategies have been undertaken. ${ }^{[4-12]}$ Research capacity is a process of individual and institutional development that leads to higher levels of competencies and capabilities to perform useful research. ${ }^{[13]}$
More recently, there are efforts to provide opportunities that involve partnerships between researchers and clinicians to produce practice-relevant knowledge, which has been referred to as collaborative applied research 10 or collaborative practice based research (CPBR). Specifically, CPBR enables the generation of clinically relevant knowledge of from different professional backgrounds working in collaborative teams with patients, their families, caregivers and communities. ${ }^{[10]}$

${ }^{*}$ Correspondence: Lianne P. Jeffs; Email: jeffs1@smh.ca; Address: Keenan Research Centre, Li Ka Shing Knowledge Institute, St. Michaels Hospital, Toronto, Ontario, M5B 1W8, Canada. 
Given that the nursing and health disciplines workforce constitute the largest workforce within health care ${ }^{[12]}$ and their proximity to patients, they are well positioned to generate clinically driven research questions and undertake research in the practice setting. ${ }^{[11]}$ However, undergraduate and postgraduate entry to practice courses may not always equip nurses and health disciplines with the competencies required to undertake research. ${ }^{[14]}$ Further, despite efforts to build research capacity through a variety of initiatives (e.g. educational programs, fellowships, funding), ${ }^{[6-8,15-17]}$ nurses and health care professionals continue to report lacking skills and confidence to conduct research due to minimal or no experience and not having enough time to participate in research. ${ }^{[1,6,12,14,18-21]}$

In this context, an Academic Health Sciences Center (AHSC) developed and hosted a competitive grants competition with a comprehensive learning approach as part of a larger strategy aimed at building CPBR. Underpinning the CPBR competition was the view that engaging point of care clinicians in research opportunities will motivate them to provide better care to patients. ${ }^{[14]}$ Part of the learning approach included undertaking a study aimed at exploring the perceptions and experiences of nurses and other health disciplines in an interprofessional, collaborative research capacity building strat- egy. This paper provides the results from this study.

\section{METHODS}

\subsection{Interprofessional Practice Based Research Team Competition (IPBR-TC) description}

As part of the Inter-professional Strategic Plan: "Living Interprofessional Excellence (2014-2016), the Interprofessional Practice Based Research Team Competition (IPBR-TC) program was developed and launched in 2015. A call went out for proposals that targeted nurses and other regulated health disciplines (with the exception of physicians) in Summer 2015. The IPBR-TC built upon a previous research capacity strategy designed specifically for nurses. ${ }^{[22]}$ The proposals had to be supported by either the manager or program director of the respective clinical area. The purpose of the IPBR-TC was to support collaborative practice-based research for nursing and health disciplines in generating clinically relevant knowledge. A review panel received 14 applications and using a rating matrix evaluating the clinical relevance, alignment with corporate priorities, scientific methods, and knowledge translation plan (see Table 1) selected five teams to receive funding to conduct their research over 2 years (September 2015 to September 2017). See Table 2 for research projects and team compositions.

Table 1. Interprofessional practice based research competition scoring matrix

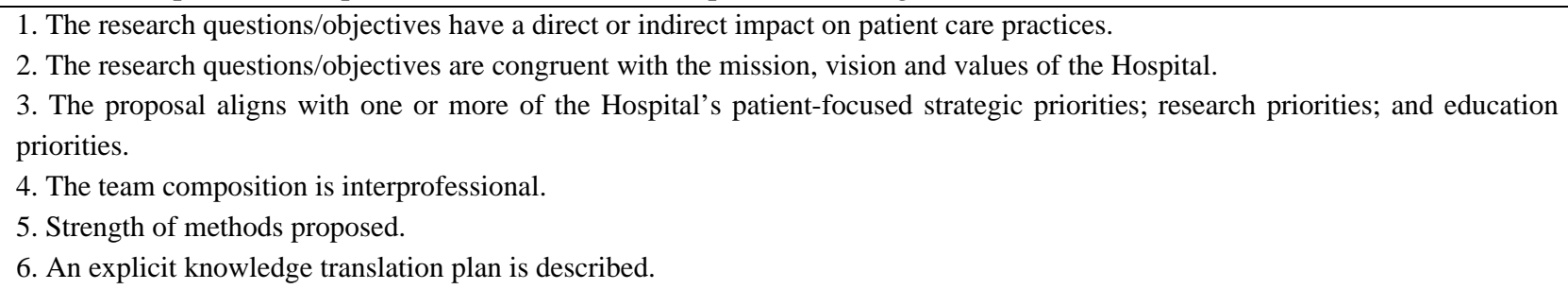

Table 2 outlines the five projects along with the team composition that were successful in securing an IPBR grant.

Over the first year, the IPBR-TC program members of the 5 teams attended a series of Communities of Practice $(\mathrm{CoP})$ meetings (see Table 3) with a mentorship team consisting of experts from the professional practice portfolio, Research Ethics Board, Health Sciences Resource Library and scientists.

\subsection{Study design and setting}

This study employed a inductive descriptive qualitative design with thematic analysis. Study participants were recruited from the five IPBR teams in an urban teaching hospital in Canada. This study was approved by the hospital's Research Ethics Board.

\subsection{Recruitment of study participants and data collec- tion procedures}

The study was introduced to IPBR-TC participants by an initial email followed by two reminders sent by a research coordinator in September 2016. The research coordinator obtained informed consent prior to the conduct of the focus groups and interviews. Participants were also asked questions on the following demographics: profession, gender, employment status, years in profession, and highest degree obtained. An interview guide adapted from previous research10 was used to focus the discussion. Three overarching questions guided the focus groups and interviews: 1) How would you describe your overall experience with the IPBR-TC? 2) What are your key learnings from participating IPBR-TC participants? 3) Describe your experience providing care since your participation in the IPBR-TC? The 
interview questions and probes were drawn from a previous study and from literature around research capacity building strategies. ${ }^{[1,2,5,6,22]}$ Research personnel conducted, digitally recorded, and transcribed the focus group and/or interview sessions. A series of 7 interviews (note a few had more than one participant) were held to accommodate the issues with scheduling. The average time was 26 minutes ranging between 15 to 36 minutes.

\subsection{Data analysis}

The interviews were analyzed using an inductive, thematic analysis process. ${ }^{[23,24]}$ This approach involves the interviews being transcribed verbatim which then are initially independently analyzed. In this study, there were three members of the research team who independently reviewed the transcripts and coded line-by-line the sections of the text. This was followed by a series of meetings whereby the three researchers went through each of their respective codes to develop a coding schema. This process involved clustering of the codes into categories (sub-themes) which at the next level of analysis were integrated into the emergent themes. The principal investigator reviewed the emergent coding schema with the original transcripts as a method to ensure rigor and trustworthiness of the data analysis.

Table 2. Project title and team composition

\begin{tabular}{|c|c|}
\hline Proposal Title & Profession \\
\hline \multirow{6}{*}{ Infant Cuddler Program } & Nurse Practitioner (Co PI) \\
\hline & Social Worker (Co PI) \\
\hline & Nurse Educator \\
\hline & Clinical Nurse Manager \\
\hline & Staff Physician $\times 2$ \\
\hline & Research Assistant \\
\hline \multirow{9}{*}{$\begin{array}{l}\text { Interprofessional Validation and Utilization of } \\
\text { Ipswich Touch Test in Persons with Diabetes }\end{array}$} & Chiropodist × 2 (Co PIs) \\
\hline & Research Assistant \\
\hline & Chiropodist $\times 2$ \\
\hline & Nurse Practitioner - Vascular \\
\hline & Registered Nurse × 6 \\
\hline & Registered Dietician $\times 2$ \\
\hline & Medical Resident \\
\hline & Clinical Nurse Specialist $\times 2$ \\
\hline & Research Manager - Orthopedic \\
\hline \multirow{4}{*}{$\begin{array}{l}\text { Moving the Urgent Care Program Forward: } \\
\text { Client Perspectives }\end{array}$} & Social Worker (Co PI) \\
\hline & Registered Nurse (Co PI) \\
\hline & Case Manager \\
\hline & Physician \\
\hline \multirow{4}{*}{$\begin{array}{l}\text { Effectiveness of early sensory stimulation of } \\
\text { patients following severe acquired brain injury }\end{array}$} & Speech Pathologist (Co PI) \\
\hline & Occupational Therapist (Co PI) \\
\hline & Speech Pathologist \\
\hline & Occupational Therapist \\
\hline \multirow{9}{*}{$\begin{array}{l}\text { Evaluating and Managing Responsive } \\
\text { Behaviours Education Curriculum }\end{array}$} & Occupational Therapist (Co PI) \\
\hline & Clinical Nurse Specialist (Co PI) \\
\hline & Occupational Therapist $\times 2$ \\
\hline & Clinical Nurse Specialist \\
\hline & Clinical Assistant \\
\hline & Register Dietician \\
\hline & Registered Nurse \\
\hline & Clinical Leader Manager \\
\hline & Corporate Nurse Educator \\
\hline
\end{tabular}


Table 3. Communities of practice learning modules

\begin{tabular}{|c|c|}
\hline Date & Session Outline \\
\hline & Introduction to IPBR Program \\
\hline September 2015 & $\begin{array}{l}\text { The first COP was the introductory session. The IPBR teams were given an opportunity to introduce their team } \\
\text { members and to give a brief introduction of their research question. An opportunity was also given for each IPBR } \\
\text { team to meet with their research mentor, REB coordinator and library counsellor. At this session the IPBR teams } \\
\text { were also asked what COP topics they would like to see covered. }\end{array}$ \\
\hline & Survey Design, Measurement and Qualitative Research Methods \\
\hline December 2015 & $\begin{array}{l}\text { The second COP focused on study design and methods tailored to cover the design and methods that were } \\
\text { identified in the } 5 \text { research teams' projects which included survey design, selecting measures and qualitative } \\
\text { design. Three of the research mentors volunteered to provide the content for this COP. }\end{array}$ \\
\hline \multirow{4}{*}{ February 2016} & Research Ethics Board - After Initial Approval \\
\hline & $\begin{array}{l}\text { The first part of the third CoP was geared to introduce the IPBR teams on what happens once you get REB } \\
\text { approval. As most of the participants in this initiative were new to research many did not know how to enact } \\
\text { measures that is warranted in the collection and storing of data and of the ongoing REB requirements over the life } \\
\text { of the study. As the REB director was one of the IPBR Advisory Committee members she was invited to lead the } \\
\text { session. Topics covered in her presentation included: Conduct of Research; Informed Consent; Revisions, } \\
\text { Amendments, Changes; Continuing Review; Reporting; Privacy \& Confidentiality. }\end{array}$ \\
\hline & Library Inservice - Endnote Session \\
\hline & The second part of the COP, IPBR teams attended a session on how to set up and use EndNote. \\
\hline \multirow[b]{2}{*}{ March 2016} & Communicating Your Research Projects and Stakeholder Mapping \\
\hline & $\begin{array}{l}\text { The fourth COP session was an interactive session on how to communicate the key concepts of your research } \\
\text { study. The learning objectives and content covered in this COP included: 1) identifying key concepts on how to } \\
\text { maintain momentum and build awareness through effective communication; 2) creating messages for a variety of } \\
\text { strategies to engage key stakeholders; and 3) practicing delivering verbal messages for different stakeholders. }\end{array}$ \\
\hline
\end{tabular}

\section{Findings}

\subsection{Sample characteristics}

The overall sample included 12 participants who were female with 5 nurses, 3 occupational therapists, 2 social workers, 1 speech language pathologist and 1 research coordinator who participated in the study. Eleven participants worked full time with one part-time with 7 having more than 16 years experience, 2 between 11-15 years experience, 2 between 6-10 years experience, and 1 with a year experience. Ten participants had graduate education with 1 having a university degree and 1 a college diploma.

\subsection{Themes}

The following five themes emerged in the narrative dataset of focus groups and interviews: learning to navigate the research landscape in a shared space; providing an opportunity and support for interprofessional clinician driven research; enriching the research process by engaging different disciplines to collaborate; impacting current and future collaborative practice; and keeping the momentum amidst experiencing challenges.

\subsubsection{Learning to navigate the research landscape in a shared space}

This theme captures how participants, mainly through participation in the communities of practice, learned to navigate the research landscape. Most participants shared how they valued learning from each other by listening to what other teams had done to move their research project forward and viewed their peers as motivating. They also appreciated not having to do their research in isolation of others. As one participant described not having to 'start from scratch' and being able to 'dovetail' with something that another team was doing. For some participants it was a learning curve having minimal exposure to research previously. For others is was learning about existing resources within the hospital in preparing the ethics submission, library services, recruiting study participants, and accessing resources. All learners (regardless of what they knew about research) described the content delivered by research experts and administrative leads as informative. The curriculum included research specific topics (e.g. research ethics boards, library session on how to manage references, methods) and broader topic areas including how to communicate to a variety of stakeholders what research was being undertaken and why (rationale). 
This theme is illustrated in the following narratives.

"Coming to the community of practice sessions and hearing where other teams are at have reignited things for us and has been a constant refocus on the research. There's certainly a lot of topics that were useful and I think we've given feedback along the way of things we would like to know more about." (Interview 2)

"Having a group discussion listening to other peoples' ideas, what worked, begging, stealing and freely borrowing from others, that helps because when you go to the COPs you hear about something that is already implemented so why start from scratch because you can already add onto or dovetail to something that someone is already doing." (Interview 5)

"In our small team, we have an idea that we want to do research collaboratively with the emergency department. Now I feel much more prepared to put an idea together because I know from coming to the community of practice, who I can reach out to help put something together. It is a big organization but there are so many people available to support so sometimes it is just knowing who to talk to you is a big step in and of itself." (Focus Group 1 Participant 5)

Study participants also learned about the research process during participation in the CoPs and having to apply their learnings into their research projects. Some participants were involved in several aspects of the research process (e.g. writing of proposal, ethics submission, data collection, and data analysis), while others participated in data collection methods that they had not been exposed to before. An appreciation for how detailed the research process is and that it involves several steps emerged as a key learning. For others, developing and understanding how to manage (e.g. securing of resources, budgeting) the research project earlier in the competition process was recommended as a key strategy. See the following quotes for examples of this theme.

"It is not my strength to do focus groups that was a learning curve for me. Most of the studies that I have been involved in that use observational methods like chart reviews or survey distribution as the methods. This is my first time leading a research study that used a focus group as a methodology." (Interview 1)

"The vision that allowed access to individuals to learn research methods and see transformation or outcomes from their projects at the bedside it's been a remarkable experience. It was incredibly well organized, our every step that has supported this and thinking about the actual qualitative and quantitative analysis that we've done through this study just tactical issues around writing the research proposal, from the experiencing responses from the research ethics board just all of that dealing with confidentially were new learnings for me. Focus group analysis and managing a research budget were helpful skills." (Interview 3)

"If there had been more planning in the very beginning, I think for me personally, I was so naïve when I first started about what is involved in research. It was just so exciting to put this proposal together and then from the very first meeting we are talking about REB but I did not know anything about research and I had no idea what was involved. I wish there had been a few CoPs in the beginning just to talk about what is this going to look like in the long run and be a bit more thought out and give us a bit more information before we even talk about." (Focus Group 1 Participant 2)

\subsubsection{Providing an opportunity and support for clinician driven research}

This theme encompasses how study participants described appreciation for being provided the opportunity to participate and have support both locally (e.g. by other staff on their unit and manager) and corporately (e.g. professional practice, research ethics, library services, and senior administration for the funding) for their participation and selected research projects. Access to a mentorship team consisting of a research mentor, a REB mentor, and librarian mentor was perceived as instrumental in moving the research teams' projects forward. For example, research mentors were often mentioned by teams for their role in refining the methods and walking them through how to conduct and analyse their respective datasets. The focus of the initiative being clinician driven research were also highlighted as important by study participants. See examples below of this theme.

"Our REB coordinator was really good. She spent a lot of time going through each of the questions with us when we were able to meet with her. That was really useful. It was my first time going through a REB application and probably the same for you, having gone through that with an actual coordinator and her telling us 
what they were looking for helped a lot. Maybe it was also because we had the conflicts because we had to take her comments and bring it back to the group. It was kind of messy that way. But things worked out I think." (Focus Group 1 Participant 3)

"I think we have learned as a team is that we do need cheerleaders. We need more people to motivate the entire group to continue you on with the momentum and keeping going because we do have a lot of different sites because we are not physically at those sites. We need people to be physically to be cheering along the side. 'You are doing great work, let's keep going'." (Focus Group 1 Participant 4)

"I found our mentor was very needed. We kind of screamed for help, she responded. She made time to meet with us not just emails. I think it really helped that she had more knowledge of the actual program than we did so if there was a little nuance question she would have a readymade answer for us, which was helpful." (Focus Group 2 Participant 2)

\subsubsection{Enriching the research process by engaging differ- ent disciplines to collaborate}

The third theme that emerged was enriching the research process by engaging different disciplines to collaborate. This theme reflected how beneficial study participants viewed the have different team members that were multi-disciplinary with different competencies and experiences. For some teams, members were brought from across the hospital involving local clinical and corporate staff (e.g. professional practice and staff aligned with the Senior Friendly corporate initiative). The majority of the teams described having a good team that collectively had complementary skills and competencies to undertake the research project. Within each of the teams, various roles were assigned and assumed to complete the various tasks associated with their selected research project. This theme is exemplified with the following narrative:

"The study is inherently split so we all know our responsibilities will be in terms of the clinicians any way so that is built and I think everyone that has agreed to join has been motivated." (Interview 2)

"It is a great opportunity for allied health to get involved in research, you have the support, information, mentoring, funding all of those things that weren't really available it has been a unique opportunity. We lucked out with who is on our team because it is a matter of having a bit of a vision. Everyone needs a role or they will not be engaged. In our situation our manager had a role to play [and has] taken on ownership of this that has helped. Our educators helped us training our volunteers and monthly meeting with the nurses and that helps to anchor the program. Our chief is the one that has the vision in terms of research and the interprofessional collaboration. Then we have our person who runs the substance abuse in pregnancy program, she has been a little bit, maybe, behind the scenes. (Focus Group 1 Participant 1)

"The only thing that made it workable was that both of us have very different skill sets so when one person wasn't able to tolerate the other could. We didn't as a group go down the sinkhole together. By any stretch, we were always able to work with the flexibility. Somebody was flexible enough to be able to say ok I can manage this so therefore I will do that." (Focus Group 2 Participant 1)

On the other hand, some study participants described having tensions with role clarity and hierarchies around certain aspects of conducting research (e.g. hiring research assistants) and how to engage team members in the research study. Some participants recommended content around interprofessional competences, including effective team building and understanding of how roles, needs to be included earlier in the learning sessions (CoPs) to assist them in navigating these tensions. The following quotes provide examples of this sub-theme.

"If you are not a physician or not a researcher do not expect you can do any of the hiring. Some basic guidelines about the hierarchies and who not to go to and some of the structural pieces around what to do and what not to do. We did not intentionally step on anybody's toes and yet it would not surprise me if we stepped on peoples' toes." (Focus Group 1 Participant 1)

"I think we have people on our team for the sake of having them on our team where there hasn't really been any input into the actual activities in the study." (Focus Group 1 Participant 2)

"Reflecting back there is other ways we can work around who is the PI and there can be other peo- 
ple who can actually run and be alongside with those people to continue to engage people. I think that engagement of other members is another key concept, how can we keep engagement from others who may not be as involved." (Focus Group 1 Participant 4)

\subsubsection{Impacting current and future collaborative practice}

This fourth theme captures how study participants described how their participation in IPBR-TC impacted their current practice and insights on future impact on collaborative practice. Several study participants shared that they would continue to be involved in interprofessional collaborations on their unit and some provided examples of other initiatives that their work was building momentum for being non-physician led (e.g. family integrated care program aligned with the infant cuddler program) and spreading to other units and hospitals (e.g. managing responsive behaviors education strategy). Some participants also described how they planned to be more thoughtful in future research activities and leverage the network they established in the CoP and participating in IPBR-TC in future initiatives. This theme is elucidated in the following narrative excerpts.

"We wanted to pilot this study in one inpatient unit hoping that the learning that we get from the evaluation piece will help us roll out of the initiative to other areas. There is great value in it because it is a corporate initiative and we are spreading the work now. We learned a lot from our pilot unit. We reviewed the curriculum. We revised and tailored it to the next unit so we are starting in two units now." (Interview 1)

"That work we started for this project has now expanded to the TAHSN [regionally based health sciences network] workgroup and we have actually an abstract in at an international geriatric conference related to a piece of that work. So the work is evolving." (Interview 3)

"There has been a change in our practice from the nature of our project. For my next project when this over I know I am going to be a lot more thoughtful and know what is involved and really have a good idea of if this is appropriate as research, is that too big, is that manageable, who do we need to get involved. I think it will be really helpful going forward to kind of be better informed going into things and know what resources to access. Even just having the connections as well in this room has been really helpful, the networking opportunities." (Focus Group 1 Participant 2)

"Some of the projects that people are working on have the potential to impact care not just here but across acute care sites not only in the city but beyond which is really impressive." (Focus Group 1 Participant 5)

\subsubsection{Keeping the momentum amidst experiencing chal- lenges}

The fifth theme includes a series of challenges identified by study participants during their participation in the IPBR-TC and implementation of their research projects. Despite initial buy-in from unit leadership, all teams struggled with prioritizing clinical demands with lack of protected time to participate in the CoPs and conduct of their selected research projects. For some the time commitment was more than they originally expected and required 'goodwill' and going above and beyond time at work to focus on their research projects. There were also challenges engaging others on the team due to the lack of time available for the research project and being short-staffed. The following narrative illustrates this challenge:

"In the last CoP there was a common thread described by most of the research groups and that is the challenge of engaging the research team. They have similar issues in engaging clinicians who may have limited time to be engaged because they don't have dedicated time for research. I did try, I actually set up scheduled time to meet with them but there were some changes in the pilot areas as well." (Interview 1)

"Had everything run more smoothly in terms of not having so much turnover in our group, not having our clinical coverage, we could have probably gotten through it in two years otherwise it's just these unforeseeable things. I think we've always known our clinical case load still has to come first and this is something we'd like to add in there but we realized we can't affect the care we provide day to day either so we just haven't really committed until we know we can manage it." (Interview 2)

"The fact that we were initially told because this is [hospital] competition we did not anticipate being told that this would have to be done on our own time outside of our work day. At the same time people were saying "congratulations thank you for winning this award for our department' and we are going, thanks for putting our 
department on the map'. Yes, know you will be doing it on your own time because you won't have work time to do it as long as that is clearly understood. Nor will you get overtime for it even though it benefits the hospitals etc. So we didn't anticipate that. It was upsetting to the manager that you were being called off the floor for that long once every however many weeks. There was always the condition how are you going to make up the time. It's of enough interest the two of use, we said fine whatever, we will just go ahead and do it anyways." (Focus Group 2 Participant 1)

Other challenges that study participants described experiencing included logistical challenges with preparing (e.g. accessing REB mentor) and obtaining ethics approval (e.g. long duration); managing the operational aspects including organizing the staffing requirements (e.g. challenges getting transcription done), recruitment (e.g. not having a dedicated person to conduct data collection), and budget (e.g. how much amount to budget for what and small overall budget of $\$ 5,000)$. Having a short time for proposal submission and changes to team and leadership were also identified as challenges. Study participants recommended having dedicated research positions, more funding and protected time to engage in research. Examples of these challenges and recommendations are provided below:

"My patients don't necessarily qualify because most of them have ulcers or something on their feet so it is rare for me to be able to recruit the patients so the main setting is the vascular surgery clinic. The nurse in the clinic identifies the patients then I drop everything and go over and either consent to the patient depending on what is required." (Interview 4)

"I understand that this is a competition and I don't think it would be feasible to have the workshops before the competition to show people how to get your team together but in the actual competition it asked to mention what are the roles of all these people. That was the opportunity to figure out who should be doing what and because of the deadline for submission was a little short people did not have too much time to figure out who is really supposed to be doing what." (Focus Group 1 Participant 3)

"It was a lot of, who to go to? How to do it? How quickly will it be done? There is time restrictions on everything and so at the beginning we planned for most of the known challenges we anticipated plus some room in between. REB 6 months we didn't really think it would take that long. Our understanding because it is this type of project it will be pushed forward a little bit faster. A rollercoaster. You go in thinking you know what you are in for and then there is a challenge right that makes it, partially interesting partially frustrating that you even signed up for that. It's like spinning in circles. It's the waiting and not going anywhere and no results." (Focus Group 2 Participant 2)

\section{Discussion}

The themes that emerged in this study provide insight into the perceptions and experiences of nurses and health disciplines participating in a collaborative practice research capacity building strategy. Our study findings add to a small empirical base, consisting of mainly survey evaluation results, on interprofessional research capacity building strategies.

Our study highlights and elucidates the value of learning research together and from each other within an interprofessional collaborative CoP approach. This finding is consistent with other findings that highlight the importance that CoPs have in designing learning spaces that enable collaborative, reflective discourse on issues that participants are or have experienced in research ${ }^{[22]}$ and quality improvement ${ }^{[25,26]}$ capacity building efforts. ${ }^{[27,28]}$ In our study, participants described being able to move their research project forward and navigate the system by learning how to conduct research by experts; applying their learnings to their research project; being motivated by and provided with tactical tips from other participating interprofessional research teams; and knowing what resources existed. By participating in learning activities created to cultivate a deeper understanding of research and improvement ${ }^{[29]}$ and sharing successes and failures (dos and don't), teams were able to discern what strategies others employed that might be useful in their research efforts. Our finding that study participants are motivated to spread their research project to other units to impact care is similar to previous research that reported that nurses ${ }^{[22]}$ and health disciplines14 engage in research as a means to deliver the best service possible and achieve the best outcomes for their patients.

Within these CoPs, teams were provided support (e.g. resources) and a mentorship team (researcher, librarian, and ethics coordinator) to conduct research. Collectively, the mentorship team guided them through the research processes (e.g. methods, ethics submission, literature reviews, logistics) and kept them focused to work on their research project. This 
finding is consistent with other literature that delineates the paramount role that mentors have in working with clinicians to develop their research skills. ${ }^{[8,14,22]}$ This relationship requires having sufficient time for for the mentors to work with the teams to develop and conduct a research project with clear deliverables, timelines, and assigned responsibilites. ${ }^{[15]}$ Support for mentorship and targeted team-based education for building research capacity has been reported in other studies. ${ }^{[11,16]}$ In our study, the finding around the key role of the unit manager supporting their local research team is consistent with other work that identified managers to positively influence the unit culture and actively support research engagement. ${ }^{[4]}$

Participating teams described the value of having an interprofessional collaborative team to work on the research project adding to the evolving literature base on the value of CPBR ${ }^{[14]}$ In our study, participants felt that the unique - yet complimentary - competencies and experiences from the variety of disciplines comprising the team enriched the research process and was a key enabler to conducting their research project. Having a shared vision identified has also been reported elsewhere as a strength in conducting CPBR. ${ }^{[15]}$ Further, study participants expressed interest in participating in collaborative practice and future research opportunities and that they would leverage the network established through participating in the IPBR-TC strategy. A team-based approach to build research capacity was reported to be effective in developing linkages and collaborations with participating members in primary care. ${ }^{[16]}$

The challenges experienced by study participants were consistent with the literature including not have sufficient protected time ${ }^{[6,14,20-22]}$ or resources (e.g. budget, research staff). ${ }^{[6]}$ Similar to other studies, our study participants described the challenges prioritizing the delivery of clinical service amidst balancing work and life ${ }^{[14,15]}$ and engaging other colleagues in the research project. ${ }^{[15]}$ In our study, this challenge was most predominant with health disciplines who often did not have another colleague to be able to backfill while they attended the CoP or worked on their research project. Other work has identified similar challenges that health disciplines have in conducting research. ${ }^{[14,21]}$

The following limitations need to be taken into consideration when interpreting the study findings. First, the study was conducted at one academic teaching hospital with a small sample size $(n=12)$ and may not be transferrable to other settings. Second, selection bias might be present due to highly motivated teams that participated.

\section{Conclusion}

Our study demonstrated the value of providing opportunity for nurses and health disciplines to engage in CPBR and undertake a project relevant to clinical practice that adds to the body of knowledge on the value of collaborative practice based research capacity building strategies ${ }^{[6-8,15-17]}$ and communities of practice. ${ }^{[22,27,28]}$ Despite the valuing of the experience, challenges emerged that necessitate future efforts to provide support for nurses and health disciplines participating in research capacity building strategies. At a minimum, nurses and health disciplines need to have protected time and backfill, ${ }^{[6,14,20-22]}$ research personnel to assist with data collection and analysis, and funds to support knowledge translation activities (e.g., open access journal fees and conferences) ${ }^{[11]}$ Future educational strategies should consider including a team based, CoP approach with a mentorship team $^{[15]}$ to build collaborative practice based research. Future directions for research include mixed methods evaluation of the impact and outcomes associated with collaborative practice research capacity building on a larger scale in Canada.

\section{CONFLICTS OF INTEREST DisClOSURE}

The authors declare that there is no conflict of interest.

\section{REFERENCES}

[1] Cooke J. A framework to evaluate research capacity building in health care. BMC Fam Pract. 2005; 6: 44. PMid:16253133 https : //doi.org/10.1186/1471-2296-6-44

[2] Pirkis J, Goldfeld S, Peacock S, et al. Assessing the capacity of the health services research community in Australia and New Zealand. Aust. N. Z. Health Policy. 2005.

[3] Harding K, Lynch L, Porter J, et al. Organisational benefits of a strong research culture in a health service: a systematic review. Aust Health Rev. 2016.

[4] Perry L, Grange A, Heyman B, et al. Stakeholders' perceptions of a research capacity development project for nurses, midwives and allied health professionals. J Nurs Manag. 2008; 16(3): 315-326. PMid:18324991 https://doi.org/10.1111/j.1365-2834. 20 $07.00801 . \mathrm{x}$

[5] Hulcombe J, Sturgess J, Souvlis T, et al. An approach to building research capacity for health practitioners in a public health environment: an organisational perspective. Aust Health Rev. 2014; 38(3): 252-8. PMid:24785693 https://doi.org/10.1071/AH13066

[6] Pickstone C, Nancarrow S, Cooke J, et al. Building research capacity in the allied health professions. Evid Policy. 2008; 4(1): 53-68. https://doi .org/10.1332/174426408783477864

[7] Ried K, Farmer EA, Weston KM. Bursaries, writing grants and fellowships: a strategy to develop research capacity in primary 
health care. BMC Fam Pract. 2007; 8: 19. PMid:17408497 https : //doi.org/10.1186/1471-2296-8-19

[8] Golenko X, Pager S, Holden L. A thematic analysis of the role of the organisation in building allied health research capacity: a senior managers' perspective. BMC Health Serv Res. 2012; 12: 276. PMid:22920443 https: //doi.org/10.1186/1472-6963-12-2 76

[9] Jeffs L, Smith O, Beswick S, et al. Investing in nursing research in practice settings: A blueprint for building capacity. Canadian Journal of Nursing Leadership. 2013; 26(4): 44-59. https ://doi .org/10 $.12927 /$ cjnl .2013 .23630

[10] King G, Thomson N, Rothstein M, et al. Integrating research, clinical care, and education in academic health science centers. Journal of Health Organization and Management. 2016; 30(7): 1140-1150. PMid:27700478 https://doi.org/10.1108/JHOM-11-2015-0 177

[11] Wenke RJ, Ward EC, Hickman I, et al. Allied health research positions: a qualitative evaluation of their impact. Health Research Policy and Systems. 2017; 15: 6. PMid:28166817 https://doi .org/10 .1186/s12961-016-0166-4

[12] Wenke R, Mickan S. The role and impact of research positions within health care settings in allied health: A systematic review. BMC Health Serv Res. 2016; 16: 355. PMid:27495229 https: //doi.org/10.1186/s12913-016-1606-0

[13] Trostle J. Research capacity building in international health: definitions, evaluations, and strategies for success. Social Science Medicine. 1992; 35: 1321-24. https://doi.org/10.1016/0277-9536(92 ) $90035-0$

[14] Pager S, Holden L, Golenko X. Motivators, enablers, and barriers to building allied health research capacity. J Multidiscip Healthc. 2012; 5: 53-9. PMid:22396626 https://doi .org/10.2147/JMDH. S27 638

[15] Holden L, Pager S, Golenko X, et al. Evaluating a team-based approach to research capacity building using a matched-pairs study design. BMC Family Practice. 2012; 13: 16. PMid:22409832 https://doi.org/10.1186/1471-2296-13-16

[16] Cooke J, Nancarrow S, Dyas J, et al. An evaluation of the 'Designated Research Team' approach to building research capacity in primary care. BMC Fam Pract. 2008; 9: 37. PMid:18588685 https://doi.org/10.1186/1471-2296-9-37

[17] Bates I, Akoto AYO, Ansong D, et al. Evaluating health research capacity building: an evidence-based tool. PLoS Medicine/Public Library of Science. 2006; 3(8): e299.
[18] Kelly KP, Turner A, Speroni KG, et al. National survey of hospital nursing research, part 2: facilitators and hindrances. Journal of Nursing Administration. 2013; 43(1): 18-23. PMid:23207718 https://doi.org/10.1097/NNA.0b013e3182786029

[19] Stephens D, Nicholas T, Sandra G. Leggat. Research experience and research interests of allied health professionals. Journal of Allied Health. 2009 Winter; 38(4): e107-11. PMid:20011811

[20] Finch E, Cornwell P, Ward EC, et al. Factors influencing research engagement: research interest, confidence and experience in an Australian speech-language pathology workforce. BMC Health Serv Res. 2013; 13: 144. PMid:23597184 https://doi .org/10.1186/14 72-6963-13-144

[21] Orme J, Powell J. Building research capacity in social work: process and issues. Br J Soc Work. 2008; 38(5): 988-1008.

[22] Jeffs L, Smith O, Wilson G, et al. Building Knowledge for Safer Care: Nursing Research Advancing Practice. Journal of Nursing Care Quality. 2009; 24(3): 257-262. PMid:19525767 https ://doi .org/10 $.1097 / \mathrm{NCQ} .0 \mathrm{~b} 013 \mathrm{e} 3181955 \mathrm{f} 59$

[23] Braun V, Clarke V. Using thematic analysis in psychology. Qual Res Psychol. 2006; 3: 77-101. https://doi.org/10.1191/147808 8706qp063oa

[24] Ryan GW, Bernard HR. Techniques to Identify Themes. Field Methods. 2003; 15(1): 85-109. https://doi.org/10.1177/152582 $2 \times 02239569$

[25] Jeffs L, McShane J, Flintoft V, et al. Contextualizing Learning to Improve Care Using a Collaborative Communities of Practice Approach. BMC Health Services Research. 2016; 16: 464. PMid:27590455 https://doi.org/10.1186/s12913-016-1566-4

[26] Jeffs L, Abramovich IA, Hayes C, et al. Implementing an Interprofessional Patient Safety Learning Initiative: Insights from Participants, Project Leads and Steering Committee Members. BMJ Qual Saf. 2013; 0: 1-8.

[27] Wenger E. Communities of practice and social learning systems. Organization. 2000; 7(2): 225-46. https://doi.org/10.1177/13 5050840072002

[28] Wenger E, McDermott RA, Snyder WC. Cultivating communities of practice: a guide to managing knowledge. Boston, MA: Harvard Business School Press; 2002.

[29] Nembhard IM, Tucker AL. Deliberate Learning to Improve Performance in Dynamic Service Settings: Evidence from Hospital Intensive Care Units. Organ Sci. 2011; 22(4): 907-22. https: //doi.org/10.1287/orsc. 1100.0570 